\title{
Editorial
}

\section{West Meets East}

\author{
Giuseppe Remuzzi
}

IRCCS - Mario Negri Institute for Pharmacological Research, and Department of Medicine, Azienda Ospedaliera, Ospedale Papa Giovanni XXIII, Bergamo, Italy

\section{Kidney Disease: A Global Health Problem}

Recent findings from the Global Burden Disease (GBD) 2013 study have highlighted kidney disease as an important cause for global mortality [1]. The number of deaths from chronic kidney disease (CKD) was estimated to be 956,200 in 2013, which is a $37 \%$ increase from 1990, one of the largest increases among the top 50 causes of deaths [1]. Thus, kidney disease constitutes a global public health priority, also underlined by the fact that the number of end-stage renal disease $(E S R D)$ patients receiving renal replacement therapy is estimated at more than 1.4 million worldwide, with an annual growth rate of $8 \%$ [2]. With a population that is ongoing, step increases in the incidence of type 2 diabetes mellitus and hypertension are driving this growth, putting an enormous burden on health care resources [3]. CKD occurs in $\sim 10 \%$ of the population, but it must not be assumed that kidney disease is entirely contained within the cardiovascular risk envelope [4]. In emerging countries, up to $40 \%$ of patients identified with CKD in screening programs do not have diabetes or any cardiovascular disease $[3,4]$. Such patients with kidney disease are often young, and the health and societal costs of the progression of their renal disease are high and prolonged.

\section{Innovative Drug Development to Tackle Renal Disease Progression}

Effective strategies can slow or even halt the progression of CKD and reduce the risk of cardiovascular mortality. Foremost are the control of blood pressure and uri- nary protein excretion, preferably with agents that block the renin-angiotensin pathway, and good glycemic control for diabetic patients [5]. Human studies have shown that proteinuria is an independent predictor of progression and that its reduction is renoprotective [6]. At comparable blood pressure control, inhibitors of the reninangiotensin system (RAS), including angiotensin-converting enzyme (ACE) inhibitors and angiotensin II type 1 receptor blockers, reduce proteinuria, slow the progression to ESRD, and even improve the kidney function more effectively than non-RAS inhibitor therapy, achieving disease regression in some cases [6]. Furthermore, in patients with diabetes, RAS inhibitors delay the onset of microalbuminuria, and ACE inhibitors may reduce the excess cardiovascular mortality associated with diabetes renal disease [7]. Nevertheless, a significant number of patients with CKD still progress to ESRD, highlighting the need for clinical trials that develop and test novel disease-specific treatments as add-on to the currently available renoprotective therapies.

Recent advances in understanding the pathogenesis of kidney diseases have provided a strong rationale for novel therapeutic approaches to specific renal diseases that will hopefully address important unmet needs in the field [8]. Advances in renal medicine commonly rise from the Western countries and set their influence on the Eastern nations. Unfortunately, there are pitfalls in the current drug development paradigm in our countries, including in the design, conduct, and evaluation of clinical trials, which should raise awareness and not be repeated by Eastern countries. Issues of particular relevance to clinical trials in nephrology include the inappropriate use of

\section{KARGER 125}

(c) 2015 S. Karger AG, Base

2296-9381/15/0011-0004\$39.50/0
Giuseppe Remuzzi, MD, FRCP

IRCCS - Mario Negri Institute for Pharmacological Research

Centro Anna Maria Astori, Science and Technology Park 'Kilometro Rosso'

Via Stezzano 87, IT-24126 Bergamo (Italy)

E-Mail giuseppe.remuzzi@ marionegri.it 
placebo, publications of reports that emphasize potential treatment benefits over adverse reactions, and the sometimes dubious impartiality of independent guidelines [9]. Behind these shortcomings, however, there is the complexity of how the academia, pharmaceutical industry and regulatory authorities currently interact for drug development in clinical trials.

\section{Academia, Industry and Authority Interaction}

The authorization and use of a drug is dependent upon the decision made by the relevant regulatory authorities, such as the Food and Drug Administration (FDA) in the USA, the European Medicines Agency (EMA) in Europe, and the Pharmaceuticals and Medical Device Agency in Japan. These authorities, in turn, are governed by specific laws. The academia is another major stakeholder, including all non-profit organizations (such as universities, scientific institutions and scientific societies), that can potentially have an important role in influencing the behavior of prescribers. Patients and consumer associations also have an important function: patients participate in clinical trials, and consumer associations should always be consulted in decisions concerning priorities in research. Finally, the for-profit pharmaceutical companies maintain what is essentially a monopoly in the development of new drugs, as well as being the principal participants in promotional activities, sales and lobbying [10].

Interactions between the academia, the pharmaceutical industry and regulatory authorities are of paramount importance for ensuring the quality, efficacy and safety of drugs in clinical use. These interactions have in some cases proven to be ineffective or inappropriate, with the result that economic interests have sometimes prevailed over the rights of patients. Regrettably, the academia has not always provided the critical component that could moderate the ability of industry to influence the decisions of regulatory authorities. The scientific literature is full of reports describing pitfalls and limitations in the design, conduct and conclusions of controlled trials [10-16]. In many drug trials, the role of the academia is limited to the recruitment of patients. The academia is, therefore, often neither truly independent of the trial process, nor fully able to participate in drafting the protocol, reporting the outcomes and analysis of the results before publication and the final report $[17,18]$, which can result in a number of problems that conflict with the ethics of clinical investigations. Therefore, there is need for the academia to develop a more effective relationship with both regulatory authorities and the pharmaceutical industry. Private economic interests must not be allowed to outweigh the need of patients for drugs with renal therapeutic value. Although there are substantial differences between US and European legislation [19], clearly both regions have a very similar need for improved, patient-oriented legislations.

\section{Importance of Independent Trials}

The influence of industry sponsorship on the outcome of clinical trials is evident in the way results are obtained and presented. For instance, a secondary outcome analysis of the results of a study financed by the manufacturer of sevelamer (a non-calcium based phosphate binder), indicated that, in terms of patient survival, sevelamer was superior to calcium-containing binders such as calcium acetate or calcium carbonate in patients with ESRD receiving dialysis [20]. The manufacturer's study involved 127 patients, but in another unrelated trial with approximately 2,000 patients, the mortality rates associated with the two types of phosphate binders were not significantly different [21]. Another example of how clinical trial end points are selected for commercial benefits is provided by trials comparing the efficacy of the immunosuppressive agents mycophenolate mofetil and azathioprine in solid organ transplantation. Three ground-breaking prospective randomized double-blind clinical trials were conducted in a total of 1,593 kidney transplant recipients who were all given an immunosuppressive regimen that included cyclosporine and steroids [22-24]. A pooled analysis of the three studies found that mycophenolate mofetil significantly reduced the incidence of biopsy-proven rejection episodes in the first year after transplantation: 19.8 and $16.5 \%$ in the mycophenolate mofetil 2 and $3 \mathrm{~g} /$ day groups, respectively, versus $40.8 \%$ for placebo/azathioprine [25]. On the basis of these trial findings, the EMA and the FDA approved mycophenolate mofetil for the prevention of graft rejection in patients after renal transplantation. In subsequent years, mycophenolate mofetil progressively replaced azathioprine as part of the standard immunosuppressive treatment for preventing rejection in solid organ and bone marrow transplantation in most medical centers worldwide [26]. However, subsequent academic studies of organ transplant recipients found no real difference in clinical efficacy between mycophenolate mofetil and azathioprine [27-30]. Nevertheless, a subsequent meta-analysis of data from 3,143 kidney transplant recipients showed a clinical benefit of mycophenolate mofetil over azathioprine in the reduction of 
acute rejection risk and, possibly, improved graft survival [31]. However, when the analysis was restricted to the six academic studies, the benefit of mycophenolate mofetil over azathioprine was less apparent. This situation highlights the current discrepancy between academic studies, which find a nonclinical difference between mycophenolate mofetil and azathioprine in organ transplantation, and the perception that mycophenolate mofetil has superior clinical efficacy, which is mainly fuelled by the results of industry-funded drug-registration trials. Evidencebased drug selection is also economically important, as more than EUR 3,400 per patient per year would be saved by using azathioprine $(100 \mathrm{mg})$ instead of mycophenolate mofetil ( $2 \mathrm{~g})$ daily to prevent acute rejection in organ transplantation [32].

\section{Improving Clinical Trials}

One of the functions of the academia is to help make safe and effective drugs available to patients; therefore, an effective and appropriate relationship with the industry area is always needed. A key aim of the academia should be preserving the rights of the patients who generously participate in clinical trials, even those involving some level of personal risk. Moreover, independent trials are essential for all interventions, not only in fields in which the industry has no direct interest. Very little is known about the comparative benefits of drugs that have the same therapeutic indications in terms of relative therapeutic end points and adverse effects. This lack of knowledge exists because the industry seldom seeks to know the position of its own drug in relation to the products of another manufacturer. Instead, the reports of many industry-sponsored trials stress minor variations in outcomes that are often misleading or irrelevant, rather than highlighting evidence that is actually useful to clinicians and patients. Similarly, comparative studies to establish the optimal dose and duration of treatment are rarely a priority for the industry, but they should be for the academia. Manufacturers' trials often compare drugs of the same class in nonequivalent doses, whereby misleading results that favor their own products are produced. The academia should encourage protocols for the development of new drugs that include testing for superiority versus existing therapies, use of preplanned statistical analyses, and the publication of all results, even for trials with negative findings [33-35].

Furthermore, the selection of patients is critical to the accuracy and usefulness of clinical trials, because results obtained in adult men might not necessarily apply to children, women or elderly persons who are often excluded from clinical trials. The growing population of elderly people who frequently have several diseases and, therefore, require multiple drugs [36] calls for an improved representation of this population in clinical trials. Thus, it is the duty of the academia to move in the direction of better-designed trials that answer meaningful clinical questions in relevant populations and to urge that resources be made available at national and international levels to fund independent clinical trials. Such trials are in the interest of both patients and national health services.

To this purpose, it is of note that the International Society of Nephrology (ISN) has appointed the Advisory Committee of Clinical Trials and Studies (ISN-ACCTS) to facilitate the development and execution of clinical trials in a highly ethical framework worldwide, which is particularly needed in developing countries. This program ensures access to timely and unbiased expert education and advice for both independent and industry investigators. The ISN-ACCTS is working to protect the rights of clinical trial participants, both investigators and patients, especially in developing countries.

In conclusion, Eastern countries have to look at the West in the context of deriving motivation and support in performing clinical trials that will aid innovations and strategies for renal care relevant to the local community needs. Nevertheless, while the East has learned from other countries in renal healthcare delivery and research, it has much to share for reciprocal benefit. Eminent nephrologists from East Asia have played a key role to open China to the Western world nephrology and scientific communities. There are now increasing opportunities to promote a new nephrology partnership for joining efforts between West and East in more technologically advanced clinical and laboratory research to address the many unsolved problems around acute kidney disease and CKD for the benefit of millions of patients who are awaiting solutions for their renal disease. Improvements in the drug development process that intend to balance public needs with commercial aims and ensure effective drug evaluation by regulatory authorities could be a critical starting point of the West and East cooperation.

\section{Disclosure Statement}

The author has no conflicts of interest to declare. 


\section{References}

1 GBD 2013 Mortality and Causes of Death Collaborators: Global, regional, and national age-sex specific all-cause and cause-specific mortality for 240 causes of death, 1990-2013: a systematic analysis for the Global Burden of Disease Study 2013. Lancet 2015;385:117171.

- White SL, Chadban SJ, Jan S, Chapman JR, Cass A: How can we achieve global equity in provision of renal replacement therapy? Bull World Health Organ 2008;86:229-237.

-3 Couser WG, Remuzzi G, Mendis S, Tonelli M: The contribution of chronic kidney disease to the global burden of major noncommunicable diseases. Kidney Int 2011;80:1258-1270.

4 Jha V, Garcia-Garcia G, Iseki K, Li Z, Naicker S, Plattner B, Saran R, Wang AY, Yang CW: Chronic kidney disease: global dimension and perspectives. Lancet 2013;382:260-272.

-5 Group KDIGOKCW: KDIGO 2012 clinical practice guideline for the evaluation and management of chronic kidney disease. Kidney International 2013;(suppl 3):1-150.

6 6 Ruggenenti P, Cravedi P, Remuzzi G: Mechanisms and treatment of CKD. J Am Soc Nephrol 2012;23:1917-1928.

7 Ruggenenti P, Porrini E, Motterlini N, Perna A, Ilieva AP, Iliev IP, Dodesini AR, Trevisan R, Bossi A, Sampietro G, Capitoni E, Gaspari F, Rubis N, Ene-Iordache B, Remuzzi G: Measurable urinary albumin predicts cardiovascular risk among normoalbuminuric patients with type 2 diabetes. J Am Soc Nephrol 2012; 23:1717-1724.

8 Cravedi P, Remuzzi G, Ruggenenti P: Rituximab in primary membranous nephropathy: first-line therapy, why not? Nephron Clin Pract 2014;128:261-269.

-9 Garattini S, Perico N: Drug development: how academia, industry and authorities interact. Nat Rev Nephrol 2014;10:602-610.

10 Goldacre B: Bad Pharma: How Drug Companies Mislead Doctors and Harm Patients. London, Fourth Estate, Ltd., 2012, pp 1-448.

-11 Altman DG, Moher D: Declaration of transparency for each research article. BMJ 2013; 347:f4796.

12 Chalmers I, Bracken MB, Djulbegovic B, Garattini S, Grant J, Gulmezoglu AM, Howells DW, Ioannidis JP, Oliver S: How to increase value and reduce waste when research priorities are set. Lancet 2014;383:156-165.

13 Chalmers I, Glasziou P: Avoidable waste in the production and reporting of research evidence. Lancet 2009;374:86-89.

14 Garattini S, Bertele V: Ethics in clinical research. J Hepatol 2009;51:792-797.

15 Jones CW, Handler L, Crowell KE, Keil LG, Weaver MA, Platts-Mills TF: Non-publica- tion of large randomized clinical trials: cross sectional analysis. BMJ 2013;347:f6104.

16 Kleinert S, Horton R: How should medical science change? Lancet 2014;383:197-198.

17 Garattini S, Bertele V, Bertolini G: A failed attempt at collaboration. BMJ 2013;347:f5354.

18 Lundh A, Krogsboll LT, Gotzsche PC: Sponsors' participation in conduct and reporting of industry trials: a descriptive study. Trials 2012;13:146.

19 Vitry A, Lexchin J, Sasich L, Dupin-Spriet T, Reed T, Bertele V, Garattini S, Toop L, Hurley E: Provision of information on regulatory authorities' websites. Intern Med J 2008;38:559567.

20 Block GA, Raggi P, Bellasi A, Kooienga L, Spiegel DM: Mortality effect of coronary calcification and phosphate binder choice in incident hemodialysis patients. Kidney Int 2007;71:438-441.

21 St Peter WL, Liu J, Weinhandl E, Fan Q: A comparison of sevelamer and calcium-based phosphate binders on mortality, hospitalization, and morbidity in hemodialysis: a secondary analysis of the Dialysis Clinical Outcomes Revisited (DCOR) randomized trial using claims data. Am J Kidney Dis 2008;51: 445-454.

22 Placebo-controlled study of mycophenolate mofetil combined with cyclosporin and corticosteroids for prevention of acute rejection. European Mycophenolate Mofetil Cooperative Study Group. Lancet 1995;345:13211325.

23 Sollinger HW: Mycophenolate mofetil for the prevention of acute rejection in primary cadaveric renal allograft recipients. U.S. Renal Transplant Mycophenolate Mofetil Study Group. Transplantation 1995;60:225-232.

24 A blinded, randomized clinical trial of mycophenolate mofetil for the prevention of acute rejection in cadaveric renal transplantation. The Tricontinental Mycophenolate Mofetil Renal Transplantation Study Group. Transplantation 1996;61:1029-1037.

25 Halloran P, Mathew T, Tomlanovich S, Groth C, Hooftman L, Barker C: Mycophenolate mofetil in renal allograft recipients: a pooled efficacy analysis of three randomized, double-blind, clinical studies in prevention of rejection. The International Mycophenolate Mofetil Renal Transplant Study Groups. Transplantation 1997;63:39-47.

26 Mele TS, Halloran PF: The use of mycophenolate mofetil in transplant recipients. Immunopharmacology 2000;47:215-245.

27 Remuzzi G, Cravedi P, Costantini M, Lesti M, Ganeva M, Gherardi G, Ene-Iordache B, Gotti E, Donati D, Salvadori M, Sandrini S,
Segoloni G, Federico S, Rigotti P, Sparacino V, Ruggenenti P: Mycophenolate mofetil versus azathioprine for prevention of chronic allograft dysfunction in renal transplantation: the MYSS follow-up randomized, controlled clinical trial. J Am Soc Nephrol 2007;18: 1973-1985.

28 Remuzzi G, Lesti M, Gotti E, Ganeva M, Dimitrov BD, Ene-Iordache B, Gherardi G, Donati D, Salvadori M, Sandrini S, Valente U, Segoloni G, Mourad G, Federico S, Rigotti P, Sparacino V, Bosmans JL, Perico N, Ruggenenti P: Mycophenolate mofetil versus azathioprine for prevention of acute rejection in renal transplantation (MYSS): a randomised trial. Lancet 2004;364:503-512.

29 Shah S, Collett D, Johnson R, Thuraisingham RC, Raftery MJ, Rudge CJ, Yaqoob MM: Long-term graft outcome with mycophenolate mofetil and azathioprine: A paired kidney analysis. Transplantation 2006;82:16341639.

30 McNeil K, Glanville AR, Wahlers T, Knoop C, Speich R, Mamelok RD, Maurer J, Ives J, Corris PA: Comparison of mycophenolate mofetil and azathioprine for prevention of bronchiolitis obliterans syndrome in de novo lung transplant recipients. Transplantation 2006; 81:998-1003.

31 Knight SR, Russell NK, Barcena L, Morris PJ: Mycophenolate mofetil decreases acute rejection and may improve graft survival in renal transplant recipients when compared with azathioprine: a systematic review. Transplantation 2009;87:785-794.

32 Germani G, Pleguezuelo M, Villamil F, Vaghjiani S, Tsochatzis E, Andreana L, Burroughs AK: Azathioprine in liver transplantation: a reevaluation of its use and a comparison with mycophenolate mofetil. Am J Transplant 2009;9:1725-1731.

33 Chan AW, Hrobjartsson A, Haahr MT, Gotzsche PC, Altman DG: Empirical evidence for selective reporting of outcomes in randomized trials: comparison of protocols to published articles. JAMA 2004;291:2457-2465.

34 Easterbrook PJ, Berlin JA, Gopalan R, Matthews DR: Publication bias in clinical research. Lancet 1991;337:867-872.

35 Hahn S, Williamson PR, Hutton JL: Investigation of within-study selective reporting in clinical research: follow-up of applications submitted to a local research ethics committee. J Eval Clin Pract 2002;8:353-359.

36 Becker ML, Visser LE, van Gelder T, Hofman A, Stricker BH: Increasing exposure to drugdrug interactions between 1992 and 2005 in people aged $>$ or $=55$ years. Drugs Aging 2008;25:145-152. 